\title{
«A CAUSA DEL SOL». UNA LECTURA DE EL EXTRANJERO DE CAMUS
}

\author{
AMALIA QUEVEDO \\ Universidad de La Sabana, Colombia
}

\begin{abstract}
RESUMEN: Es hoy, tras la aparición del libro póstumo y auto-biográfico de Camus que lleva por título El primer hombre, cuando mejor preparados estamos para entender esa novela compleja e inagotable que es El Extranjero. Ahora que el existencialismo ha perdido vigencia social, podemos echar mano de otras claves hermenéuticas, que no son ni políticas, ni ideológicas, ni existencialistas, para leer El extranjero. Una de ellas la provee el viejo concepto de acedia, ligado al demonio meridiano. El artículo examina asimismo el empleo que Camus hace de la noción de tedio, emparentada con la de acedia.
\end{abstract}

PALABRAS CLAVE: Camus, tedio, acedia, sol.

\section{"Because of the sun». A reading of The Stranger by Camus}

ABSTRACT: Nowadays, after the publication of Albert Camus's posthumous and autobiographical book, The first Man, we are finally entitled to understand the complex and inexhaustible Camusian novel, The Stranger. Now that existentialism has lost much of his social presence, we can have recourse to different hermeneutical keys, neither political, nor ideological or existentialist, that would allow us to read The Stranger. One of them is provided by the ancient concept of accidia, linked to the noontide demon. The article examines as well the use Camus makes of the notion of tedium, intrinsically related to that of accidia.

KEY WORDS: Camus, tedium, accidia, sun.

\section{INTRODUCCIÓN}

Abundan las lecturas éticas, políticas y hasta jurídicas de esa inagotable novela de Albert Camus que lleva por título El extranjero (1942). Pero quizás la más conocida y comúnmente aceptada sea la lectura existencialista, que tiñe de sabor sartreano la novela de Camus. Desde hace casi setenta años, la náusea, la angustia y el sinsentido se combinan en forma caleidoscópica para definir el horizonte interpretativo de la novela camusiana, la óptica prevalente bajo la cual ésta ha sido leída.

La aparición, en 1994, de la obra póstuma El primer hombre, en la que Camus estaba trabajando cuando lo sorprendió la muerte, ha sacado a la luz no sólo un manuscrito bello y genial, profundo y tierno, sino también un hecho innegable: es ahora cuando mejor preparados estamos para leer y entender a Camus: ahora que la sombra de Sartre ya no lo eclipsa, ahora que el comunismo ha perdido vigencia histórica y social, y el existencialismo ha dejado de tener la palabra.

La lectura atenta de El primer hombre invita a acallar las voces siempre demasiado estridentes de la literatura académica y política que se quiere intérprete fidedigno y portador legítimo de las ideas del escritor argelino. El lector contemporáneo, eximido de pagar tributo a los imperativos históricos y culturales que condicionaban a los contemporáneos de Camus, se encuentra en una posición privilegiada para escuchar el eco de voces arcanas y olvidadas que resuena en sus palabras. Ajeno al ruido que en la segunda mitad del siglo xx provocaba el existencialismo, el nuevo lector de Camus quiere prestar oído a la sangre del autor, descubrir las corrientes ocultas que surcan su pensamiento, desvelar ancestrales influjos mediterráneos. 
La clave sobre la que haré bascular mi lectura de El extranjero es precisamente una experiencia originalmente mediterránea, la de la acedia, hoy en buena parte olvidada, cuando no reducida a una frívola pereza en materia religiosa. Pero antes quisiera ahondar en una noción antigua, emparentada con ella. Me refiero a la noción de tedio, un concepto de origen romano, que se forja a la sombra de la filosofía estoica. En el taedium vitae (tedio de la vida) confluyen el férreo determinismo de los estoicos y su voluntad ética de superar el dolor, alcanzar la virtud y descansar en la impasibilidad. No siendo el hombre más que un prisionero de la necesidad, nada tiene de extraño que ante esa perspectiva surja el concepto de tedio, el fastidio de vivir.

\section{Prolegómenos del tedio}

Acalladas las pasiones, y en un mundo en el que rige el más férreo determinismo, el tedio no se hace esperar. Séneca es el primero en formular su noción: en el tratado $D e$ tranquillitate animi aborda algunos de los temas que, a lo largo de la historia, irán de par con el problema del tedio. La tranquilidad es el plácido estado del hombre virtuoso que ni se exalta ni se abate. De este estado ideal se apartan tanto los que están vejados por su propia liviandad, por el tedio y por la continua mudanza de propósitos, como esos otros que hechos unos holgazanes se pasan la vida bostezando. Añade a éstos los que andan mudándose de un lado a otro ${ }^{1}$.

Séneca fustiga al hombre inquieto y deseoso de acción, que apela al recurso de refugiarse en el ocio y en los estudios solitarios, y luego no soporta ni la casa, ni la soledad, ni las paredes, y contra su voluntad se ve abandonado a sí mismo. Brota entonces el tedio y el descontento de sí mismo, el desasosiego de un ánimo nunca asentado, y la triste y agria paciencia con que soporta su propia ociosidad. Aparecen la tristeza y la languidez y las mil fluctuaciones de una mente incierta ${ }^{2}$.

Según Séneca, el ánimo humano es por naturaleza ágil y pronto al movimiento: toda materia que lo excite y lo distraiga le es grata. «Tan pronto como se concluye un viaje se emprende el siguiente, y los espectáculos se suceden unos a otros de modo que, como dice Lucrecio, cada uno huye siempre de sí mismo. Pero ¿de qué sirve huir cuando no se puede escapar? ¿No se sigue uno a sí mismo, llegando a ser para sí un compañero inoportuno? Y así debemos saber que la molestia que padecemos no proviene de los lugares, sino de nosotros mismos; flacos somos para soportarlo todo y no tenemos aguante para sufrir mucho tiempo ni el trabajo, ni el placer, ni a nosotros mismos, ni a ninguna otra cosa. Es así como algunos prefirieron morir, cuando vieron que de tanto cambiar volvían siempre a lo mismo, pues ya no quedaba nada nuevo ni inexplorado. Les fastidió la vida e incluso el mundo, y de sus bocas cansadas de delicias salió este lamento: ¡Siempre lo mismo!»³

Que el ánimo del hombre se inclina naturalmente al movimiento, a la acción, es una idea que retoma Pascal, y que Voltaire comenta en los siguientes términos: «Como el fuego tiende hacia arriba, y la piedra hacia abajo, así el hombre ha nacido para la acción » ${ }^{4}$.

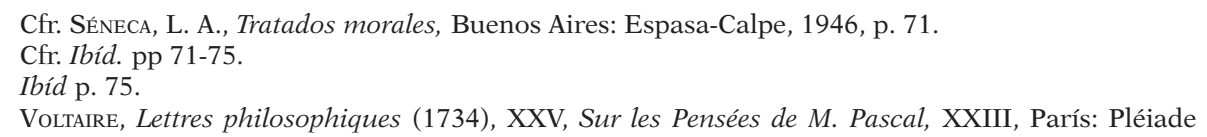


Sin embargo, es enfermizo el no poder permanecer en el mismo lugar o en la misma posición durante largo tiempo, y el demandar del cambio el remedio a este malestar.

En la historia de Occidente, los viajes, los cambios y los desplazamientos aparecerán una y otra vez como medios para combatir el tedio. Sin embargo, ya en el siglo i Séneca pone en entredicho esta solución que se queda en lo externo y no acierta el núcleo del problema. El tedio tiene su sede en el hombre, y nadie puede huir de sí mismo, como no puede tampoco saltar sobre su propia sombra ${ }^{5}$.

Desde antiguo, la soledad ha sido siempre aliada del tedio, y esto sin ignorar que es posible estar solo en medio de una muchedumbre, en una fiesta abarrotada de gente, en cualquier tipo de reunión social. Séneca insiste en la necesidad de alternar la reclusión en uno mismo y el contacto con los demás, buscando unas veces la soledad y otras la compañía. El aislamiento hace que deseemos la vida social, y ésta a su vez nos hace desear el recogimiento solitario. Cada uno es remedio del otro. La soledad nos cura del aborrecimiento de la multitud, y la multitud, del tedio de la soledad (taedium solitudinis) ${ }^{6}$.

Tedio, pereza que se derrama en bostezos, y mudanza continua aparecen juntos por primera vez en el pensamiento de Séneca, bajo el signo del vicio que se opone a la estabilidad anímica. Tres siglos más tarde, los padres del desierto amalgamarán en forma peculiar las nociones de tedio y mudanza continua para acuñar un nuevo concepto: el de acedia.

\section{El ENNUI}

En la lengua francesa, que es la de Camus, la palabra ennui no aparece hasta el siglo XII. De acuerdo con la etimología más aceptada, ennui viene del bajo latín inodiare (sustantivo inodium), sinónimo del clásico taedere: aburrirse, estar a disgusto, hastiarse, que en el siglo de Augusto da lugar al vocablo taedium: tedio. Con el paso del tiempo, el sentido del odio (in odio esse) se va matizando; en el siglo xII el ennui aparece más bien como fatiga o tristeza, en el XIV como monotonía y fastidio.

Ennui significa aburrimiento o tedio, pero también pena, tristeza, aflicción, desespero, desolación, malestar, desasosiego, impresión de vacío, fastidio. Por su riqueza semántica, este término francés aparece frecuentemente sin traducir. La lengua castellana presenta un problema adicional: carece de un verbo correspondiente al sustantivo tedio, lo que obliga a traducir el francés s'ennuyer por términos como aburrirse o hastiarse, que en el fondo no le hacen justicia.

Ennui es un concepto polimorfo que adquiere con el tiempo una gran importancia en la literatura y la filosofía. Entendido como tedio, el ennui jalona la literatura francesa desde el poeta tardo-medieval Charles D’Orléans hasta el pensador de origen rumano Emil Cioran. En ese largo decurso encontramos pensadores insignes como Montaigne y Pascal, mujeres de letras como las marquesas Madame de Maintenon y Madame du Deffand, ilustrados como Helvetius y Voltaire, románticos como Chateaubriand y Sénancour, escritores modernos de la talla de Flaubert, Baudelaire y Proust. También en la obra de Albert Camus hace presencia el tema del tedio, del ennui y sus derivados.

Ya en la primera página de la novela de 1947 que lleva por título La peste, aparece el aburrimiento: «El modo más cómodo de conocer una ciudad —escribe allí Camus— es averiguar cómo se trabaja en ella, cómo se ama y cómo se muere. En nuestra ciudad,

5 Cfr. SÉneca, L. A., Tratados morales, pp. 72-76.

6 Cfr. Ibid, pp. 89-90. 
por efecto del clima, todo ello se hace igual, con el mismo aire frenético y ausente. Es decir, que se aburre uno y se dedica a adquirir hábitos» ${ }^{7}$. En sus cuadernos, Camus confiesa que el verdadero tema de esta novela es la separación. A esos hombres a los que la plaga había apartado de sus seres queridos, de sus lugares habituales, de sus rutinas - y a los que el escritor llama los separados-, se los veía, una vez extinguido en ellos el fuego del sufrimiento inicial, «en las esquinas, en los cafés o en casa de los amigos, plácidos y distraídos, con miradas tan llenas de tedio que, por culpa de ellos, toda la ciudad parecía una sala de espera» ${ }^{8}$.

La vinculación del aburrimiento con la espera es un lugar común. Otro lugar común, que también encontramos en El primer hombre, y que todos hemos experimentado, es el aburrimiento de la tarde del domingo. Cuenta Camus que «la abuela lo arrastraba a casa de la tía el domingo por la tarde, y él se aburría soberanamente, salvo cuando el tío Michel, que era carretero y también se aburría escuchando aquellas conversaciones en el comedor oscuro, (...) lo llevaba al establo»?.

\section{Alegorías del tedio}

Cabe preguntarse si, en esta trayectoria que abarca siglos, Camus aporta algo nuevo al concepto del tedio, un tedio que Flaubert había caracterizado mediante la metáfora de la araña silenciosa que teje su tela en el corazón de Emma Bovary, y Madame du Deffand por su parte había asimilado al gusano solitario que todo lo absorbe, haciendo que nada nos aproveche.

El tedio de Flaubert, a través de la alegoría animal de la araña, envuelve a su víctima en una baba tibia y lenta que la atrapa y paraliza. Refiriéndose a Emma Bovary, Flaubert revela que «el tedio, araña silenciosa, tejía su tela en la sombra, en todos los rincones de su corazón ${ }^{10}$. Cada sonrisa de Emma oculta un bostezo de aburrimiento y hastío. Si por fuera se entretiene, al volver a casa desfallece al calor del hogar y siente recaer sobre ella un tedio aun más pesado. El propio Flaubert, en sus cartas, se queja con insistencia del tedio que "como una lepra lo corroe», y asegura no tener «nada más que deseos inmensos e insaciables, un tedio atroz y continuos bostezos» ${ }^{11}$.

Ahora bien, lo propio del tedio, lo que lo hace traicionero, es que él no nace tanto del deseo insaciable cuanto del deseo saciado. Si todos nuestros deseos fueran satisfechos, caeríamos, según Condillac, en la incapacidad de satisfacer la más apremiante de nuestras necesidades: la de desear ${ }^{12}$. "No nos quedaría entonces más que un vacío abrumador, un tedio de todo y de nosotros mismos» ${ }^{13}$.

El deseo satisfecho, toda satisfacción, produce tedio. Rousseau lo reconoce en las confesiones que pone en la pluma de Madame de Wolmar, la nueva Eloísa: "No veo más que motivos de contento en todas partes, y sin embargo no estoy contenta; una languidez secreta se insinúa en el fondo de mi corazón; yo lo siento vacío e hinchado; la adhesión que

Camus, A., La peste. Buenos Aires: Editorial Sudamericana, 1999, p. 9.

Ibid. p. 169.

Camus, A., El primer hombre. Madrid: Alianza, 2010, vol. 5, p. 535.

10 Cfr. Flaubert, G., Madame Bovary. Madrid: Akal, 2007, p. 69.

11 Flaubert, G., Carta a Lousie Colet del 13 de diciembre de 1846 y carta a Ernest Chevalier del 14 de noviembre de 1840. Cfr. Correspondance. París: Gallimard-Pléiade, 1973.

12 La misma idea está presente en el Cándido de Voltaire.

13 Condillac, Étienne Bonnot de, Traité des animaux. Amsterdam: Jombert, 1766, p. 151. 
tengo por todo lo que me es querido no basta para ocuparlo; le queda una fuerza inútil con la que no sabe qué hacer. Esta pena es extraña, lo concedo, pero no por eso es menos real. Amigo mío, soy demasiado feliz; la felicidad me hastía y aburre (le bonheur m'ennuie $)^{14}$.

Cuando dicta las cartas que le merecerán un lugar en la literatura francesa, la marquesa du Deffand es una mujer sola, vieja y ciega, asediada por el miedo a la soledad y al tedio. Atrás han quedado los días en que ella regentaba uno de los mejores salones de París y disfrutaba del trato y la conversación de hombres ilustres como Montesquieu, Voltaire o D'Alembert. En una de sus cartas, Madame du Deffand asevera que «el tedio es el gusano solitario que todo lo absorbe y hace que nada nos aproveche» ${ }^{15}$. Y en otra insiste: «Lo que se opone a mi felicidad es un tedio que se asemeja al gusano solitario que consume todo aquello que podría hacerme feliz» ${ }^{16}$.

Tanto la araña silenciosa en la sombra, de Flaubert, como el gusano solitario, de Madame du Deffand, asimilan el tedio a un animal pequeño y ordinario, pero eficaz. Mientras que la araña del tedio paraliza las fuerzas del hombre, el gusano ávido que todo lo absorbe sugiere una vampirización de origen modesto y proporciones exiguas, pero implacable.

Animales oscuros e insignificantes de la vida diaria, la araña y el gusano, metáforas del tedio, apuntan a una depredación lenta y callada. Lo propio del tedio, y que a la vez lo hace insoslayable, es que nace y se nutre de lo ordinario, de lo cotidiano. "Yo era lo que sois todos vosotros - declara Flaubert-, un hombre que vive, que duerme, que come, metido en sí mismo, y que dentro de sí halla los mismos senderos mil veces recorridos, las mismas profundidades inexploradas, horribles y tediosas ${ }^{17}$.

\section{LA CIRCULARIDAD CAMUSIANA}

También Camus propone una alegoría animal del tedio. En una nota para La peste, escrita en enero de 1941 y recogida en el cuaderno 3, el escritor argelino habla de Orán como de «una ciudad que vuelve la espalda al mar y va construyéndose en torno a sí misma, a la manera de los caracoles. Uno anda errante en este laberinto buscando el mar como la señal de Ariadna. Y da vueltas en redondo en todas estas calles faltas de gracia y feas. Al final, el Minotauro devora a los oraneses: es el tedio (ennui) ${ }^{18}$.

Contrastan la rudeza y la talla del animal mitológico con la simplicidad y la pequeñez del gusano y la araña. El resultado es no obstante el mismo: el tedio consume, paraliza, devora a los hombres. Pero no hay que perder de vista que si la bestia antropófaga representa al tedio, es porque ella es inseparable del laberinto. Camus no parangona el tedio a un monstruo cualquiera, sino al que se oculta en el laberinto y devora a las víctimas que han fatigado sus pasos ciegos y vanos en los dédalos interminables.

No parece a primera vista que Camus aporte nada relevante a la concepción del tedio; pero si se analizan sus textos, se advierte que, como él lo entiende, el tedio presenta una

14 Rousseau, J.-J., Julia o la nueva Eloísa. Madrid: Akal, 2007, p.736. A fin de no eclipsar ninguna de las dimensiones contenidas en el término francés ennui - la de hastío o fastidio y la de aburrimiento o tedio-, he echado mano del recurso de traducir ennui por esta perífrasis.

15 Du Deffand, M., Carta a Horace Walpole del 7 de febrero de 1773, en Letters to the hon. Horace Walpole. London: Longman, 1810, vol. II, p. 407.

16 Ibid. p. 174.

17 Flaubert, G., Noviembre, en Obras completas. París: Du Seuil, 1994, pp. 252-253.

18 Camus, A., Carnets: Cuaderno 3. Madrid: Alianza, 2010, vol. 1, p. 588. 
inconfundible circularidad. Al adoptar la forma del laberinto, esta circularidad entraña no sólo la idea de repetición, sino que convierte los fines y propósitos en callejones sin salida. Ya Flaubert había aludido a «los mismos senderos mil veces recorridos» y «las mismas profundidades inexploradas», pero es Camus el que pone este aspecto de relieve.

La novedad camusiana estriba en la visión circular del tedio, visión que tiene sus raíces en una experiencia de la infancia, que se recoge en El primer hombre: "Cuando la abuela, por excepción, estaba ausente o charlaba con la vecina, el niño aplastaba la nariz contra las persianas del comedor, que daban a la calle. La calzada estaba desierta. La zapatería y la mercería de enfrente habían bajado los toldos de lona roja y amarilla, una cortina de cuentas multicolores disimulaba la entrada del estanco, y en el café de Jean no había un alma, con excepción del gato que dormía, como si estuviera muerto, en la frontera entre el suelo cubierto de serrín y la acera polvorienta. El niño se volvía entonces hacia la habitación casi desnuda", y "preso entre los dos desiertos de la sombra y del sol, giraba sin cesar alrededor de la mesa, con el mismo paso precipitado, repitiendo como una letanía: “¡Me aburro! ¡Me aburro!” (Je m’ennuie!, Je m’ennuie!)»19.

\section{LA ENFERMEDAD Y SUS REMEDIOS}

Conocedora aguda y profunda del tedio, la literatura francesa, que desde Charles D’Orléans viene empapando su pluma en la bilis negra de la melancolía, reconoce en el tedio una enfermedad crónica e incurable, que a lo sumo admite fugaces y engañoso paliativos.

Madame du Deffand concibe el tedio como una enfermedad del alma, y asegura que «es la naturaleza la que, al darnos la existencia, nos aflige con este mal del que no es posible librarse ${ }^{20}$. Definido como epidemia general y enfermedad incurable para la que sólo existen paliativos, el tedio acarrea la muerte de la felicidad.

También Flaubert entiende el tedio como una enfermedad: «Yo nací aburrido; es la lepra que me carcome: me aburro de la vida, de mí, de los demás, de todo» ${ }^{21}$. Y a los diecisiete años no teme confesar: «Hay días en los que tengo una lasitud inmensa y un tedio sombrío me envuelve como un sudario adonde quiera que voy; sus pliegues me estorban e incomodan, la vida me pesa como un remordimiento. Tan joven y tan hastiado de todo» ${ }^{22}$.

\section{Espacios DEL tedio}

Aunque se infiltra en todas partes, el tedio tiene sus "paraísos». Uno de los lugares donde se agudiza y se ceba es el espacio carcelario. La ciudad de Orán, que para Camus refleja a Argelia, es como una cárcel; ya lo era antes de la peste, y lo seguirá siendo después. Todo laberinto, antes que nada, es una cárcel. Y Orán es ese dédalo feo y sin gracia donde el tedio, como el Minotauro, devora a los hombres.

19 Camus, A., El primer hombre, p. 468.

20 Du Deffand, M., Carta a Horace Walpole del 7 de febrero de 1773.

21 Flaubert, G., Carta a Lousie Colet, del 2 de diciembre de 1946.

22 Flaubert, G., Mémoires d'un fou, VIII. París: Arvensa, 2014, p. 26. 
«Dinamarca es una cárcel», se lamenta Hamlet²3. Y el filósofo danés Søren Kierkegaard, para quien el tedio es la raíz de todos los males, sentencia: «La vieja Dinamarca se hunde y esto es fatal; se hunde de tedio y esto es el colmo de la fatalidad» ${ }^{24}$.

Uno de los estigmas de toda clausura, sea laica o religiosa, bifurcada como un laberinto o comprimida como un ataúd, es el tedio. Si el tedio es en buena medida una secularización de la vieja acedia de los monjes y los anacoretas, la prisión combina, igualmente secularizados, el aislamiento de los viejos eremitas y la férrea clausura de los monasterios.

Los recursos de los que echa mano el señor Meursault para paliar el tedio que lo invade en la prisión, apenas difieren de los que empleaba el ermitaño aquejado de acedia: evocaciones, memorias, alguna distracción y, sobre todo, el sueño:

«Los primeros días fueron muy duros. Soportaba durante todo el día una náusea perpetua. Una vez más todo el problema consistía en matar el tiempo. A partir del instante en que aprendí a recordar, concluí por no aburrirme en absoluto. Me ponía a veces a pensar en mi cuarto, y, con la imaginación, salía de un rincón para volver detallando mentalmente todo lo que encontraba en el camino. Al principio lo hacía rápidamente. Pero cada vez que volvía a empezar era un poco más largo. Recordaba cada mueble, y de cada uno, cada objeto que en él se encontraba, y de cada objeto, todos los detalles, y de los detalles, una incrustación, una grieta o un borde gastado, los colores y las imperfecciones. Al mismo tiempo ensayaba no perder el hilo del inventario, hacer una enumeración completa. Es cierto que fue al cabo de algunas semanas, pero podía pasar horas nada más que con enumerar lo que se encontraba en mi cuarto. Así, cuanto más reflexionaba, más cosas desconocidas u olvidadas extraía de la memoria. Comprendí entonces que un hombre que no hubiera vivido más que un solo día podía vivir fácilmente cien años en una cárcel. Tendría bastantes recuerdos para no aburrirse ${ }^{25}$.

Dormir, y en concreto dormirse sobre los mismos códices que ya no se tenían ganas de leer, era una de las vías de escape del anacoreta atenazado por la acedia. Trece siglos más tarde, en una carta dirigida a Horace Walpole, Madame du Deffand dictamina: «Es una terrible desgracia haber nacido sujeta al tedio ${ }^{26}$. En ese estado, en el que la disipación y la lectura no aportan nada que interese o satisfaga, la añosa marquesa desea dividir su día como lo hacen según ella la mayoría de los animales, dedicando veintidós horas a dormir y dos a comer.

Tres siglos después, Camus le hace decir a Meursault en la prisión: «Existía también el sueño. Al principio dormía mal por la noche y nada durante el día. Poco a poco las noches fueron mejores y pude también dormir de día. Puedo decir que en los últimos meses dormía de dieciséis a dieciocho horas por día. Me quedaban por lo tanto seis horas para matar con comida, las necesidades naturales, los recuerdos y la historia del checoslovaco ${ }^{27}$.

Entre el jergón y la tabla de la cama, Meursault había encontrado, "casi pegado al género, un viejo trozo de periódico, amarillento y transparente. Relataba un hecho policial cuyo comienzo faltaba, pero que había debido ocurrir en Checoslovaquia ${ }^{28}$. No es la primera vez que echa mano, para paliar el tedio, de algo tan inútil como un periódico

23 ShaKesperae, W., Hamlet, acto II, escena VIII.

24 KierkegaArd, S., La rotación de los cultivos. Santiago de Chile: Benvedráis, 2005.

25 Camus, A., El extranjero. Madrid: Alianza, 1997, p. 62.

26 Du Deffand, M., Carta a Horace Walpole del 22 de marzo de 1778, en Letters to the hon. Horace Walpole, vol. III, p. 350.

27 Camus, A., El extranjero, p. 83.

28 Ibíd. p. 83. 
desactualizado: de vuelta en casa tras el entierro de su madre, confiesa: «Después del almuerzo me aburrí un poco y erré por el departamento. Resultaba cómodo cuando mamá estaba allí. Ahora es demasiado grande para mí, y he debido trasladar a mi cuarto la mesa del comedor. No vivo más que en esta habitación, entre sillas de paja un poco hundidas, el ropero cuyo espejo está amarillento, el tocador y la cama de bronce. El resto está abandonado. Un poco más tarde, por hacer algo, cogí un periódico viejo y lo leí» ${ }^{29}$.

\section{Sol y CALOR}

Es significativo el hecho de que el tedio aparezca en la primera página de La peste, cuando el autor traza el retrato de la ciudad de Orán tal como es en sí misma, antes de que se vea perturbada por la aparición de las ratas y transfigurada por la peste. "Por efecto del clima» — señala Camus—, en Orán, trabajar, amar y morir, «todo ello se hace igual $»^{30}$. La plaga es sin duda alguna una buena aliada del tedio, pero no es su causa; el principal responsable del tedio es el calor. Por esta razón, su estación privilegiada es el verano, lo cual no se debe tanto a las vacaciones, a la falta de un quehacer y a la pausa escolar, cuanto al sol intenso y al calor abrasador. «Para todos nuestros conciudadanos - observa el narrador de La peste una vez que ésta ha estallado-, este cielo de verano, estas calles que palidecían bajo los matices del polvo y del tedio, tenían el mismo sentido amenazador que la centena de muertos que pesaba sobre la ciudad cada día. El sol incesante, esas horas con sabor a sueño y a vacaciones, no invitaban como antes a las fiestas del agua y de la carne. Por el contrario, sonaban a hueco en la ciudad cerrada y silenciosa. Habían perdido el reflejo dorado de las estaciones felices. El sol de la peste extinguía todo color y hacía huir toda dicha» ${ }^{31}$.

El sol y el calor juegan un papel relevante en la vida y en la escritura de Albert Camus; las referencias a uno y otro son continuas. Su literatura es en buena medida paisajística, como se pone especialmente de manifiesto en obras como Las bodas o El verano. Pero Camus es, ante todo, un precursor de la psicología ambiental, que sabe discernir el influjo sutil de los factores climáticos en el comportamiento humano, desvelando así una dimensión ética que no es ajena a la naturaleza. Para entender una obra como El extranjero, hemos de rebasar los paradigmas ilustrados que privilegian la razón y adscriben toda actuación humana a un móvil racional, e intentar comprender el mundo que rodea y forja al hombre que un día será el escritor Albert Camus.

Que el tedio estival no obedece tanto a la desocupación como al calor, queda claro en el pasaje de El primer hombre donde se narra que, «durante dos años, Jacques trabajó todo el verano. En la quincallería primero, después en una agencia marítima. Cada vez veía llegar con temor el 15 de septiembre, fecha en la que debía anunciar que dejaba el empleo. Sí, se había terminado, aunque el verano fuese el mismo de antes, con su calor, su tedio. Pero había perdido lo que antes lo transfiguraba: el cielo, los espacios, las voces. (...) Dos veces por día, a las doce y a las seis, Jacques salía precipitadamente, bajaba corriendo la calle en pendiente y saltaba a los tranvías atestados, con racimos de viajeros colgados en todos los pescantes, que llevaban a los trabajadores de vuelta a sus barrios. Apretados unos contra otros en aquel calor pesado, mudos, los adultos y el niño, pensando en la casa que los esperaba, transpirando en calma, resignados a esa

29 Ibíd. p. 26.

30 Camus, A., La peste, p. 9.

31 Ibíd. p. 106. La negrilla es mía, en ésta y en las siguientes citas. 
vida dividida entre un trabajo sin alma, las largas idas y vueltas en tranvías incómodos y, para terminar, un sueño súbito. A Jacques, ciertas noches, se le acongojaba el corazón mirándolos. Hasta ese momento sólo había conocido las riquezas y las alegrías de la pobreza. Pero el calor, el tedio, la fatiga le revelaban su maldición, la del trabajo estúpido que daba ganas de llorar, cuya monotonía interminable consigue hacer que los días sean demasiado largos y la vida demasiado corta» ${ }^{32}$.

\section{El tedio metafísico}

Las citadas referencias al tedio, y muchas otras que salpican los escritos de Albert Camus, aluden al aburrimiento ordinario, que todos los hombres en un momento u otro experimentamos. Pero hay otro tedio existencial, metafísico, más profundo, que ha obligado a la lengua inglesa a adoptar para él el término francés ennui, reservando la palabra boredom para designar el aburrimiento ordinario.

Este tedio profundo, que no se confunde con el aburrimiento superficial que se expresa en el bostezo, es según Heidegger un temple de ánimo fundamental, uno de los modos basilares de la existencia ${ }^{33}$. Sartre lo perfila como una náusea ${ }^{34}$, Cioran lo describe como rayano en lo místico ${ }^{35}$. Y mucho antes que ellos, la literatura francesa del XVIII lo concibe como una especie de motor universal: De acuerdo con Helvétius, el miedo al tedio es lo que lleva a la mayoría de los hombres a actuar; en este mundo, el tedio es un resorte más universal y más potente de lo que comúnmente se piensa ${ }^{36}$.

«Conocí a un hombre - declara Jean-Baptiste Clamence en La caída- que dedicó veinte años de su vida a una casquivana, a la que le sacrificó todo, las amistades, el trabajo, y hasta la decencia de su vida, y que una noche se dio cuenta de que nunca la había amado. Lo que ocurría es que se aburría; eso era todo. Se aburría como la mayor parte de la gente. Entonces se había creado, a toda costa, una vida de complicaciones y de dramas. ¡Es menester que pase algo en nuestra vida! Aquí tiene usted la explicación de la mayor parte de los compromisos humanos. Es menester que pase algo, aunque sea el sometimiento sin amor, aunque sea la guerra o la muerte» ${ }^{37}$.

Camus no es ajeno a la historia del ennui, del aburrimiento ordinario y del tedio profundo. Sus obras abundan en referencias a aquél. Lo que cabe plantearse ahora es si también el tedio profundo aparece de algún modo en la obra de Camus, como aparece, bajo otro rostro, en La náusea de Sartre. Explícitamente, yo al menos no lo he encontrado. No he hallado ese tedio metafísico que es un fruto conceptual de la modernidad ${ }^{38}$, pero creo haber encontrado sin embargo su raíz primigenia: la acedia. Y es esta raíz primigenia la que me provee una nueva clave de lectura de la novela filosófica El extranjero.

32 CAmus, A., El primer hombre, pp. 641, 643. Ya el filósofo Immanuel Kant había visto en esta paradoja de los días que se hacen excesivamente largos y la vida que resulta demasiado breve, una propiedad del aburrimiento, al que él designa con el gráfico término alemán Langeweile: rato largo, en una palabra, tedio. Cfr. Kant, I., Anthropologie in pragmatischer Hinsicht, II, § 61.

33 Cfr. Heidegger, M., Los conceptos fundmentales de la metafísica: mundo, finitud, soledad. Madrid: Alianza, 2007, passim.

34 Cfr. SARtre, J. P., La náusea. Buenos Aires: Losada, 2008, passim.

35 Cfr. Cioran, E., Exercises d'admiration. París: Gallimard, 1986, passim.

36 Cfr. Helvétius, C.-A., De l'esprit. París: Lepetit, 1818, en Oeuvres complètes, vol. 1, p. 266.

37 Camus, A., La caída. Madrid: Alianza, 2010, vol. 4, p. 382.

38 Cfr. Quevedo, A., Melancolía y tedio. Pamplona: Eunsa, 2011, passim. 


\section{El DEMONIO MERIDIANO}

En el libro del Eclesiástico, se lee: «Los ojos del Señor están fijos en los que le aman, él es para ellos protección poderosa, refugio contra el calor del mediodía» ${ }^{39}$. Y en el salmo 90 figuran, entre las amenazas más temidas, «la peste que se propaga en las tinieblas y el azote que devasta al mediodía ${ }^{40}$. La peste la conocemos, y Camus mejor que nadie; pero ¿qué es este azote que devasta al mediodía? Desde muy antiguo se lo ha identificado con "el demonio de la acedia, al que también se llama demonio meridiano", y que es según Evagrio Póntico "el más pesado y arduo de sobrellevar de todos» ${ }^{41}$.

Apodado «el solitario», Evagrio del Ponto es un anacoreta del siglo Iv, al que debemos la primera descripción de la acedia, que él concibe como uno de los ocho espíritus de malicia. La acedia es el pecado, la tentación propia de ermitaños y monjes, la más insidiosa de todas. Evagrio describe la acedia como una debilidad del alma, que arroja al monje de su morada y le hace huir de la meditación, el estudio y la soledad, so pretexto de visitar a los enfermos. Cuando lee, el acidioso bosteza mucho, se deja llevar fácilmente por el sueño, se refriega los ojos, se estira y, quitando la mirada del libro, la fija en la pared; pero vuelto de nuevo a leer un poco, se fatiga inútilmente repitiendo el final de la palabra, cuenta las páginas, calcula los párrafos, desprecia las letras y los ornamentos, y finalmente, cerrando el libro, lo pone debajo de la cabeza y cae en un sueño no muy profundo; y luego, poco después, el hambre le despierta el alma con sus cuitas. El monje acidioso es flojo para la oración; como el enfermo no llega nunca a cargar un peso excesivo, así tampoco el acidioso se ocupará con diligencia de los deberes hacia Dios: a uno le falta la fuerza física, al otro el vigor del alma ${ }^{42}$.

Además de su parentesco con el tedio, la acedia cristiana (akédeia), que aparece en los escritos de los padres y se latiniza como acedia o ac(c)idia ${ }^{43}$, tiene también una inconfundible raíz griega. La Grecia antigua acuña el vocablo akédestos (con alfa privativa), que significa descuidado, abandonado, insepulto, y también despreocupado, desconsiderado, insensible. Los eremitas transforman esta incuria griega en la acedia cristiana, un concepto enteramente nuevo, que nace ligado a un modo de vida concreto y a una praxis ascética peculiar: la anacoresis y el incipiente monacato.

Desde su nacimiento en el siglo iv, la noción de acedia está cargada con el peso de la culpa, el hedor del pecado. Para Evagrio, la acedia no es un pecado más entre otros, es el peor de los pecados o espíritus de malicia.

\section{UNA INUSITADA CONFESIÓN}

Se ha insistido mucho en la apatía de Meursault, en su indiferencia, en su amoralidad incluso. La psicología, el derecho y la moral se devanan los sesos para identificar el móvil del inexplicable crimen perpetrado por él. Meursault lo declara con su proverbial laconismo, pero nadie parece tomarlo en serio. En el juicio, «cuando el Procurador volvió a sentarse, hubo un momento de silencio bastante largo. Yo me sentía aturdido por el calor y el asombro. (...) El Presidente contestó que, (...) antes de oír a mi abogado, le

39 Eclesiástico 34,16.

40 Salmo 90 (91), 5-6.

41 Póntico, E., Tratado práctico o El monje, cap.12, en Obras espirituales. Madrid: Ciudad Nueva, 2013, p. 140

42 Cfr. Póntico, E., De los ocho espíritus de malicia, cap. XIV.

43 En la Vulgata se encuentra bajo la forma bárbara del verbo acedior. 
complacería que precisara los motivos que habían inspirado mi acto. Mezclando un poco las palabras y dándome cuenta del ridículo, dije rápidamente que había sido a causa del sol. En la sala hubo risas ${ }^{44}$.

Se ríe la audiencia, mas no el lector. El lector sabe que es así, que el acusado dice la verdad. Desde el comienzo, el autor le ha hecho sentir todo el peso del sol aplastante y enajenador, la lacerante violencia de la intensa luminosidad, la opresión abrasadora de un calor implacable. «Persistía el mismo resplandor rojo — relata Meursault—. Sobre la arena el mar jadeaba con la respiración rápida y ahogada de las olas pequeñas. Caminaba lentamente hacia las rocas y sentía que la frente se me hinchaba bajo el sol. Todo aquel calor pesaba sobre mí y se oponía a mi avance. Y cada vez que sentía el poderoso soplo cálido sobre el rostro, apretaba los dientes, cerraba los puños en los bolsillos del pantalón, me ponía tenso todo entero para vencer al sol y a la opaca embriaguez que se derramaba sobre mí. Las mandíbulas se me crispaban ante cada espada de luz surgida de la arena, de la conchilla blanqueada o de un fragmento de vidrio. Caminé largo tiempo. (...) El ruido de las olas parecía aun más perezoso, más inmóvil que a mediodía. Era el mismo sol, la misma luz sobre la misma arena que se prolongaba aquí. Hacía ya dos horas que el día no avanzaba, dos horas que había echado el ancla en un océano de metal hirviente. (...) Pensé que me bastaba dar media vuelta y todo quedaría concluido. Pero toda una playa vibrante de sol apretábase detrás de mí $^{45}$. Di algunos pasos hacia el manantial. El árabe no se movió. (...) Esperé. El ardor del sol me llegaba hasta las mejillas y sentí las gotas de sudor amontonárseme en las cejas. Era el mismo sol del día en que había enterrado a mamá y, como entonces, sobre todo me dolían la frente y todas las venas juntas bajo la piel. Impelido por este ardor que no podía soportar más, hice un movimiento hacia adelante. Sabía que era estúpido, que no iba a librarme del sol desplazándome un paso. Pero di un paso, un solo paso hacia adelante. Y esta vez, sin levantarse, el árabe sacó el cuchillo y me lo mostró bajo el sol. La luz se inyectó en el acero y era como una larga hoja centelleante que me alcanzara en la frente. En el mismo instante el sudor amontonado en las cejas corrió de golpe sobre mis párpados y los recubrió con un velo tibio y espeso. Tenía los ojos ciegos detrás de esta cortina de lágrimas y de sal. No sentía más que los címbalos del sol sobre la frente e, indiscutiblemente, la refulgente lámina surgida del cuchillo, siempre delante de mí. La espada ardiente me roía las cejas y me penetraba en los ojos doloridos. Entonces todo vaciló. El mar cargó un soplo espeso y ardiente. Me pareció que el cielo se abría en toda su extensión para dejar que lloviera fuego. Todo mi ser se distendió y crispé la mano sobre el revólver. El gatillo cedió, toqué el vientre pulido de la culata y allí, con el ruido seco y ensordecedor, todo comenzó. Sacudí el sudor y el sol. Comprendí que había destruido el equilibrio del día, el silencio excepcional de una playa en la que había sido feliz. Entonces, tiré aún cuatro veces sobre un cuerpo inerte en el que las balas se hundían sin que se notara. Y era como cuatro breves golpes que daba en la puerta de la desgracia» ${ }^{46}$.

No he estado en Argelia, pero he visitado algún otro lugar del norte de África, y no me resulta desconocida esa opresión insoportable del sol y del calor de la que habla Meursault.

En el célebre gesto de Diógenes, que pudiendo pedirle a Alejandro Magno todo tipo de bienes, le solicita tan sólo que deje de ocultarle el sol, Kafka no ve a un cínico triunfante, sino a un loco desesperado, que ha perdido la razón metido en su barril. Apartándose de las interpretaciones al uso, Kafka no pone el acento en lo que Diógenes podía haber

44 Camus, A., El extranjero. Madrid: Alianza, 1997, p. 135.

45 Lo que quiere decir que retroceder resulta tan insoportable como seguir adelante.

46 Camus, A., El extranjero, pp. 83-86. 
obtenido del hombre más poderoso de su tiempo, dispuesto a satisfacer todos sus deseos. Kafka pone el acento en lo que Diógenes osa pedirle a Alejandro, en su deseo desatinado de exponerse al sol, «ese horrible, griego, siempre ardiente y enloquecedor sol» ${ }^{47}$.

Para nosotros, occidentales del siglo xxI, el mediodía y las horas que le siguen han perdido buena parte de su significado; la literatura de terror nos ha enseñado a temer en su lugar a la medianoche, mientras que la cultura mediterránea siempre consideró el mediodía como la hora solitaria, opresiva y silenciosa.

El mediodía es la hora funesta del pecado, la maldición blanca en que el silencio sofocante se puebla de demonios, los sentidos se embotan y la voluntad ofuscada sucumbe al sopor. En esta hora fatal el tiempo parece detenerse y no se ve al sol avanzar. La quietud pesada del mediodía resulta abrumadora y enajenante. Una larga tradición mediterránea se hace eco de esta concepción del mediodía, y en esta tradición se inserta, a mi juicio, la obra de Albert Camus.

Volvamos por un momento sobre las palabras de Meursault: «El ruido de las olas parecía aun más perezoso, más inmóvil que a mediodía. Era el mismo sol, la misma luz sobre la misma arena que se prolongaba aquí. Hacía ya dos horas que el día no avanzaba, dos horas que había echado el ancla en un océano de metal hirviente » ${ }^{48}$. Este mediodía estancado es la hora del demonio meridiano (o mesembrino), que en palabras de Evagrio «ataca desde dos horas antes del mediodía y asalta al alma hasta dos horas después de él. En primer lugar hace parecer que el sol apenas se mueve o incluso que se ha detenido y el día tiene cincuenta horas» ${ }^{49}$.

\section{ACEDIA}

En la acedia primigenia hay dos dimensiones tan antitéticas como inseparables: una dimensión que a mí me gusta llamar letárgica, y otra frenética. A finales de la Edad Media, aquella se impuso sobre ésta, hasta llegar a eclipsarla. La versión de la acedia que hereda y consolida el Renacimiento es unilateral: en ella ha desaparecido la inquietud, la ebullición, la actividad febril que, de la mano de la lasitud, la apatía y la desgana, anidaba en la acedia original. La acedia tardo-medieval y renacentista ha perdido lo que quizás podríamos llamar su bipolaridad, y ha quedado reducida a una pereza estéril, a un sopor lánguido.

Las causas de la reducción de la acedia a simple pereza son múltiples y no fáciles de discernir. Con todo, está claro que en esta evolución del concepto de acedia jugó un papel importante la iconografía de los almanaques y calendarios que tanta popularidad alcanzaron en el periodo que va del siglo xv al xvIII. La representación de la acedia mediante la figura de una mujer sentada que apoya la cara en una mano, o el motivo que llegó a ser clásico, de la hilandera que abandona el huso y dormita junto a él, sugieren inequívocamente la idea de pereza.

En la célebre mesa de los pecados capitales, que perteneciera a Felipe II y que puede admirarse hoy en el Museo del Prado, el Bosco representa la accidia mediante un hombre adormilado que ha hecho a un lado el libro que leía. Mucho menos fácil de representar pictóricamente era el acidioso hiper-activo, que pronto cayó en desuso.

47 KafKa, F., Carta a Milena del 31 de agosto de 1920 (mi traducción). Vid. Cartas a Milena. Madrid: Alianza, 2010

48 Camus, A., El extranjero, p. 61.

49 Póntico, E., Tratado práctico o El monje, cap.12, p. 141. 
Al pasar al mundo laico a finales del Medioevo, la acedia se transformó en moneda de una sola cara, perdiendo el aspecto cinético y febril: la vertiente de inestabilidad, inquietud y desasosiego, se eclipsó en favor de la vertiente inercial, de abatimiento y desgana. Una vez que rompe el cerco religioso del desierto y los monasterios y se extiende al mundo, la acedia se convierte en pereza religiosa, pereza espiritual primero, y luego en pereza sin más.

Ya en autores como Casiano se advertía una cierta tendencia a acercar la acedia a la pereza. Pero es la cultura popular la que al acoger el concepto de acedia lo modifica según las fuerzas que operan en ella. Y una de estas fuerzas, de una amplitud hoy no fácil de entender, es la creencia eficaz y operativa en los demonios. En este sentido, el demonio meridiano, vinculado a la acedia desde su origen, es en buena parte el responsable de que ella derive hacia la pereza. En segundo plano quedan los pensamientos y visones inquietantes que este demonio inspira, y la atención se centra en el sopor en que sume a sus víctimas durante el sofocante mediodía.

Pero el demonio meridiano no sólo aletarga; también agita, turba, obsesiona, enajena. A la acedia obedece asimismo la repetición vana de gestos. «Entonces — consigna Meursault-, tiré aún cuatro veces sobre un cuerpo inerte en el que las balas se hundían sin que se notara ${ }^{50}$.

\section{3. «A CAUSA DEL SOL»}

He intentado arrojar alguna luz sobre la confesión, tan desesperada como sincera, del señor Meursault ante el tribunal que lo condenará a muerte: «Mezclando un poco las palabras y dándome cuenta del ridículo, dije rápidamente que había sido a causa del sol (à cause du soleil) ${ }^{51}$. ¿Qué puede querer decir esta extraña declaración? Al desentrañar las significaciones profundas que se agazapan tras su aparente simplicidad, he procurado arrojar alguna claridad sobre ella.

Los lectores e intérpretes de Camus han enfocado la acción de Meursault desde incontables perspectivas, intentando hallar una explicación racional que dé cuenta del crimen por él cometido. Y se han enzarzado así en complejas hipótesis que casi siempre pasaban por alto la veracidad y exactitud de la explicación en apariencia demasiado simple aducida por el mismo Meursault, que confesó haber actuado así a causa del sol (à cause du soleil).

En contra de lo que podría parecer, y de las especulaciones siempre renovadas, Meursault no es un cínico ni un amoral. Lejos de ello, Meursault enlaza con la versión secularizada de la acedia primigenia, que es la que se halla en el origen del concepto moderno de tedio, y que no hay que confundir con esa visión deformante y reductiva que entiende la acedia como la pereza de los monjes.

La respuesta del acusado al presidente no es una evasiva, es una confesión. Meursault reconoce haber obrado como lo hizo por causa del sol. Y su respuesta apunta, como he intentado mostrar, a la acedia, que está lejos de ser simple; en ella están imbricados aspectos orgánicos, psicológicos y morales que no se dejan deslindar.

En un contexto moderno y secularizado, Camus rehabilita el gran poder de los elementos sobre la flaca voluntad del hombre y enlaza con una inveterada tradición

50 Camus, A., El extranjero, p. 62.

51 Ibid. p. 135. 
mediterránea que ha visto en el mediodía la hora fatal en la que los demonios o pecados (hoy los llamaríamos crímenes) se desencadenan.

Por otra parte, y aunque la respuesta de Meursault no sea frívola ni trivial, no deja de ser absurda: acertadamente absurda. Y es que eliminar a un ser humano es un acto que de suyo excluye cualquier explicación satisfactoria. Cuando Dios interroga a Caín sobre el paradero del hermano que ha muerto a manos suyas, no inquiere el porqué del crimen, sino que pregunta tan sólo: “¿Qué has hecho?»52.

Lo que he expuesto aquí se verá más claro si al desgraciado Meursault —que dista mucho de ser un cínico- le oponemos un personaje camusiano que es su antítesis: un verdadero loco y un auténtico asesino: el emperador Calígula. También él hace una confesión, pero una que no requiere ser interpretada, pues es tan inequívoca como brutal. «Es curioso. Cuando no mato, me siento solo. Los vivos no bastan para poblar el universo y alejar el tedio ${ }^{53}$.

\section{BibliogRAFÍA}

Burton, R., The Anatomy of Melancholy, 1621.

Снавот, P., Global burn-out, 2013.

ClaIr, J. (ed), Mélancolie: Génie et folie en Occident, 2005.

EIsenzweig, U., Les Jeux de l'écriture dans «L'Étranger» de Camus, 1983.

Fiтch, B. T., Narrateur et narration dans "L'Étranger» d'Albert Camus, analyse d'un fait littéraire, 1968. FöldÉnYI, L. F., Melancolía, 2008.

Hersant, Y., Mélancolies. De l'Antiquité au XXe siècle, 2005.

JANKÉlévitch, V., L'Aventure, l'Ennui, le Sérieux, 1963.

Jonnard, N., L'ennui dans la littératute européenne. Des origines à l'aube du XXe siècle, 1998.

Klibansky, R.; Panofsky, E. y SaxL, F., Saturn and Melancholy. Studies in the History of Natural Philosophy Religion and Art, 1964.

Kunn, R., The Demon of Noontide. Ennui in Western Literature, 1976.

LARUE, A., L'autre mélancolie: Acedia, ou les chambres de l'esprit, 2001.

MinoIs, G., Histoire du mal de vivre, 2003.

NABert, N. (ed), Tristesse, acédie et médecine des âmes dans la tradition monastique et cartusienne, 2005.

PăLĂșăn, D., L'ennui chez Pascal et l'acédie, 2005.

Pingaud, B., Bernard Pingaud commente L'Étranger de Camus, 1992.

Radden, J. (ed), The Nature of melancholy. From Aristotle to Kristeva, 2000.

StARoBinski, J., Histoire du traitement de la mélancolie des origines à 1900, 1960.

SVEndSEn, L., Filosofía del tedio, 2004.

Varios: Revue des Lettres modernes: Autour de «L'Étranger», série Albert Camus 16, 1995; Le Magazine Littéraire: Éloge de l'ennui, un mal nécessaire, 2001; Les écrivains et la Mélancolie, 2005.

VIGorelli, A., Il disgusto del tempo: la noia come tonalità affettiva, 2009.

Universidad de La Sabana, Colombia.

Amalia Quevedo

Facultad de Filosofía y Ciencias Humanas

amaliaqj@unisabana.edu.co

[Artículo aprobado para publicación en noviembre de 2013]

52 Génesis, 4, 10.

53 Camus, A., Calígula. Madrid: Alianza, 2010, vol. 5, p. 442. 